\title{
Where to be born or how to be born
}

A child may be born in a variety of settings, either chosen or forced by circumstances. In every historical period, there have always been options that were considered better than others and births taking place without access to them.

Midwives were mentioned in the Old Testament and Egyptian papyri. In Ancient Greece, midwives were responsible for controls during pregnancy, labor, and childbirth. Obstetricians emerged during the Roman Empire; Soranus of Ephesus, who is considered the father of obstetrics, wrote a treatise on midwifery that included theoretical and practical features on mother and child care. Health care delivery was unequal: respected midwives worked for the wealthiest families while experienced women managed those with less resources. ${ }^{1}$

The suitability to pursue the professional activity was first regulated by the Roman Senate and then by the Royal Board of Protomedici of Spain. Towards the end of the $19^{\text {th }}$ century, there was already a midwifery career and degree in place and, in the $20^{\text {th }}$ century, there were professional schools. At present, universities grant the degree of Specialist Nurse in Obstetrics-Gynecology (Midwife).

In the context of such advance-which was first empirical, then technical, and finally professionalmidwives, obstetric nurses or accoucheuses worked in homes. ${ }^{1}$

In the $20^{\text {th }}$ century, with the advancements made in the medical profession and hospital practice, childbirth was moved to facilities.

The purpose of a facility-based childbirth was to reduce maternal and neonatal morbidity and mortality. The possibility of addressing emergencies helped to prevent serious damage, and even death. The goal was achieved but childbirth was wrongly considered a disease and pregnant women and newborn infants were mistakenly seen as patients. The medical team took the leading role that had been previously assigned to the family. Isolation, interventions, and meddling have altered priorities and roles in the setting of a normal childbirth.

So? It is necessary to retrace the steps taken in the wrong way and build a model that includes adequate support, family relevance, and the necessary resources to address an emergency. The factors involved may be analyzed separately and as a whole.

The health care system may provide different levels of care, function as a network or as a nonarticulated system, and be funded publicly, privately or through health insurance plans. Children are born in all these different scenarios. The first step is antenatal care. It is important to have antenatal care and to establish the potential for complications. A risky pregnancy should be referred to a facility that offers everything necessary to manage it. A regionalized system would allow optimizing resources and accessing a timely consultation and referral.

Human resources are a key factor. At any level of care, the approach should focus on a safe, familycentered maternity center with a multicultural approach. Such arrangement offers the institutional possibility to address any emergency, always respecting the family and their culture.

Society is probably the more complex party. Experiences may be shared or individual and involve myths and truths, prejudices, information and misinformation, strengths and weaknesses. How could we analyze the situation in an objective manner, without making distorted conclusions about facilities, health care providers, and what is best for the mother and the child?

The media and health care providers have a great responsibility. Social networks have pervaded everything, without any filters. They provide easy access to information, but they may also cause extensive damage. Education and a personal discussion are probably the only ways to shed light on this confusion.

Many families choose a home childbirth because of a negative past experience or because they want a natural birth in the privacy of their home. But do these families know the positive and negative aspects of their choice?

In Argentina, 2293 babies were born at home in 2016. ${ }^{2}$ Most likely, the reason for this was different in the case of the 270 births occurred in the Autonomous City of Buenos Aires compared to the 329 cases of Chaco or the 184 cases of Formosa, the province with the highest maternal mortality rate in Argentina. As in the Greco-Roman civilization, some of these births may have been assisted by a woman of the family, others by trained providers, but all had few chances of addressing an emergency immediately.

According to a news story, ${ }^{3}$ home childbirth emerged as an alternative to obstetric violence. A better alternative is that of humanized childbirth, which many committed facilities and health care providers now offer.

The rise in non-facility based births occurring in the USA is alarming. The number of obstetric interventions has reduced but neonatal mortality has increased (1.26\% versus $0.32 \%$ or focility-based childbirths). ${ }^{4}$

In the Netherlands, the health care system has established that pregnancy, labor, childbirth, and postpartum should be assisted by midwives, either at home or in midwives clinics. Gynecologists control high-risk pregnancies as well as women 
who are referred by midwives or who have an emergency. The ambulance ride from the house to the hospital should not be more than 15 minutes.

An article states the following: "Many women who want to give birth at home cannot do it because they do not meet one of the requirements, most of them are related to health, but also because the house is not close enough to the hospital or because the delivery room is not at street level, so that the stretcher could go through in the case of an emergency." 5

The key is establishing the level of risk, getting assistance from trained health care providers, associating with a facility with a higher level of care, and ensuring immediate ambulance transport in case of an emergency.

In most cities of Argentina, this is far from feasible. An article was published on the case of a baby born at home, whose two siblings had been born by C-section. This family may have been unaware of the risks, but hasn't a health care provider discussed these with them?

If a person trained on neonatal cardiopulmonary resuscitation is not present, 10 minutes of severe hypoxia may result in irreversible consequences. For a newborn with perinatal asphyxia, urgent transfer to the health center is not enough.

If the medical team does not work as part of an institution or fails to report about a home childbirth or that emergency care may be required, the hospital may deal with the situation in a passive manner and only to a certain extent. A smooth emergency transport cannot be warranted in big cities. A traffic jam, poor respect for traffic laws, potholed streets, and protests make the ambulance ride duration unpredictable. This may not occur in cities with a more human dimension.

In relation to children's rights, when people decide to have a home childbirth, they should assume their parental responsibility.

Article 18 of the Convention on the Rights of the Child states that "both parents share the primary responsibility for their child's growth and development. Their main concern is the best interest of their child."

The Argentine National Civil and Commercial Code establishes that the main principles of parental responsibility include: a) the best interest of a child...

This is defined as care that, in light of current knowledge, ensures a child's optimal growth and development. Basic — or advanced, if necessarycardiopulmonary resuscitation should be available for every newborn infant. Vitamin K administration and hepatitis $B$ and tuberculosis immunizations are standards of care in Argentina.

If the family refuses these practices or other less questionable ones, such as examining the baby to check for normal signs or anomalies, what prevails is not the best interest of a child but the family's preferences, beliefs, and prejudices.

\section{An overview}

For humanized childbirth to become a reality, we first need health care providers and facilities to become involved because this model of care calls for more hours of work and a greater availability.

Discussions should start during pregnancy. A family should not show up at a hospital for the first time on the day of delivery with a written document stating what they want and do not want as if they were facing potential enemies. This causes unrest and defensive attitudes towards those responsible for care during hospitalization. And this is no good for providers either, who, even if they feel the same way about how childbirth should be, feel rejected during every step they take to fulfill their responsibilities.

An antenatal interview can pave the way. If there is disagreement, it would probably be best if the birth took place in a different facility. If there is agreement, doubts regarding the time and importance of each procedure will be cleared. On the day of delivery, the environment will be one of respect and collaboration, with the family and health care providers acting as a health team.

In an ideal city, where a hospital has maternal and neonatal intensive care units, a tertiary care ambulance service, good roads, trained teams willing to go to the house, and in the case of a lowrisk pregnancy at a location near the hospital, home childbirth may be considered the best option, with safe care provided by a professional, privacy and family support.

As long as these criteria are not met, the best option is a safe, family-centered maternity center.

Norma Rossato, M.D. Sanatorio de la Trinidad Palermo

http: / / dx.doi.org/10.5546/ aap.2018.eng.306

To cite: Rossato N. Where to be born or how to be born. Arch Argent Pediatr 2018;116(5):306-307.

\section{REFERENCES}

1. Hernández Garre JM. Historia de las matronas. Evolución de la ciencia y el arte de la partería. Universidad Católica de San Antonio, Murcia, España. Junio 2012. Page 235.

2. Dirección de Estadísticase Información en Salud.Ministerio de Salud de la Nación. Anuario 2016. [Accessed on: July $16^{\text {th }}$, 2018]. Available at: http: / / 190.210.218.32:301/ ChangePassword.aspx?tokken $=$ ge5UTDFHTKcMw9qY DYPpECUu2gKDkcUKW50C5iGTJ\%2bcQRlmXt3e1xCjv 7k3qEDaQzjpzEHbyNL\%2bO2Q1H3k6iAw\%3d\%3d

3. Esses JM. Parir en casa: la experiencia de un padre. Diario $\mathrm{La}$ Nación. 22 de febrero de 2018. [Accessed on: July 16 ${ }^{\text {th }}, 2018$ ]. Available at: https: / / www.lanacion.com.ar/2109107parto-domiciliario-la-experiencia-de-un-padre

4. Grunebaum A, Chervenak FA. Out-of-hospital births in the United States 2009-2014. JPerinat Med.2016 Oct1;44(7):845-849.

5. Mahiques A. Holanda cuestiona el parto en casa. Gaceta Holandesa. [Accessed on: July 16 ${ }^{\text {th }}, 2018$ ]. Available at: https: / / www.gacetaholandesa.com/ parto-en-casa 